\title{
BUGS IN GYMS - NEW ZEALAND ATTITUDES TO INFECTION RISK MANAGEMENT IN A GYM SETTING: A PILOT STUDY
}

\author{
Mary Cooper, Pavitra Dhamja, Elizabeth Youard \\ and Campbell Macgregor
}

\section{INTRODUCTION}

The spread of infectious microorganisms has been a perennial challenge globally, with an unabated effort continuing to prevent and control infection, reduce additional pressure on health systems and improve health outcomes for communities. Poor hygiene practices, lack of awareness of infection risks, and greater population density, have contributed to the challenge of addressing the spread of infectious diseases, which people's ability to travel long distances in a short amount of time continue to spread. Shared community spaces, including gyms, have been identified as areas which potentially harbour infectious diseases (Núñez-Corrales \& Jakobsson, 2020). Traditionally, cleanliness in gym facilities has been maintained to a high standard through education of patrons and staff.

Gyms can be considered 'islands' within the community, with individuals who possess a paid membership attending a physical location during set times. Worldwide, research has reinforced that various gym surfaces harbour microorganisms, including bacteria with the potential to cause disease, such as Staphylococcus (Bilung et al., 2018; Mukherjee et al., 2014). Gym users' awareness of infection risk and implementation of strategies to reduce the chance of infection, play an important role in maintaining a healthy gym environment (Meade, 2015). Strategies such as hand hygiene and disinfecting equipment have been recommended to reduce the risk of common skin infections among athletes and sports players (Zinder et al., 2010). With an 'explosion' in gym membership across New Zealand, and overall growth in the $\$ 260$ billion health and fitness industry (New Zealand Institute of Health and Fitness, 2021), there is clearly a need for greater awareness of the risk of infection in gyms (Australasian Leisure Management, 202I). Despite being an industry focused on health and wellbeing, gyms may inadvertently be putting users at risk of infection. This pilot study was undertaken in Rotorua, New Zealand, to investigate gym users' awareness of infection risk, and risk prevention behaviours.

This pilot study was conducted prior to the COVID-19 pandemic

\section{BACKGROUND}

Health and fitness centres, commonly known as gyms, form a community of people who have each purchased a membership and follow the routines and rules of the gym, defined by the paid membership. Gyms form 'islands' hosting an extended community, with members attending the set location at a set time, looking to become fitter, healthier, and stronger.

The risk of airborne infections like influenza and tuberculosis can be greater in a gym due to a high concentration of users who are exerting greater respiratory effort during intense exercise, in an indoor environment (Andrade 
et al., 2018). Andrade et al. point out that this potential risk from airborne diseases can be exacerbated by poorer quality building materials and ventilation systems in gyms.

However, the risk presented by gym equipment has become an area of attention due to its capacity to transmit pathogens. A study examining the microbial profile of a range of gym equipment identified various Staphylococcus spp, (species pluralis, aureus or multiple species) as the most common contaminants on all surfaces tested (Mukherjee et al., 2014). In a gym environment, surfaces and equipment exposed to direct skin contact have higher and more diverse bacterial colonies than floors and mats in the same area (Wood et al., 2015). Staphylococcus aureus ( $\mathrm{S}$. aureus), a common, normally occurring skin flora frequently responsible for skin infections, has been found to remain viable and highly transmissible for up to several months on non-porous surfaces (Desai et al., 201I); this would include the surfaces found on gym equipment. Common S. aureus skin infections are a concern as they may progress to involve soft tissue to produce cellulitis or life threatening septicemias; they are also implicated in multiple system infections (Lee \& Bishop, 2016). In addition, increasing S. aureus resistance to common antimicrobial drug therapies presents a challenge in treating infections effectively, increasing risk.

While Methicillin-resistant Staphylococcus aureus (MRSA) is commonly associated with hospital settings, of increasing concern is the emergence and rise in the incidence of a variant of this pathogen, community-associated Methicillin resistant Staphylococcus aureus (CA-MRSA) which produces infection in healthy people, and which is now said to be reaching epidemic proportions (Cohen, 2008). This notorious superbug is most commonly associated with deprivation and overcrowding (Loewen et al., 2017), but is increasingly emerging in novel areas and now appears more frequently among younger people (Junnila et al., 2020), athletes (Moriya et al., 2020), and those participating in contact sports (Braun \& Kahanov, 20I8). Studies of the prevalence of CA-MRSA point to a wide variation in its occurrence of between $0.3 \%$ and $23.5 \%$ among the general population of the Asia-Pacific region (Wong et al., 2018), with the rate in New Zealand increasing from 5.7 to 9.3 cases per 100,000 people over the five-year period from 2007 to 2011 (Williamson et al., 2013).

CA-MRSA is a pathogen of concern, as it has been shown to have higher levels of virulence and 'fitness', i.e. the microorganism has the capacity to flourish, and persist within a human host (Otto, 20I3)P, increasing the risk of infection among those generally involved in health promoting activities.

In a further study, Bilung et al. (2018) found $S$. aureus bacteria isolates on various fitness equipment including back machines, exercise mats, dumbbells and treadmills, with 31 of 42 swabs from fitness equipment testing positive for $S$. aureus. However, there is conflicting evidence concerning the presence of MRSA and Methicillinsensitive $S$. aureus (MSSA) isolates in the gym environment. One study of community gyms found no evidence of MRSA and MRSS colonisation in 240 cultures of swabs taken from various gym equipment and locations before and after cleaning (Ryan et al., 20II). The authors emphasised that skin-to-skin contact is the most likely source of community transmission of these contaminants, so effective cleaning mechanisms in exercise facilities and users adhering to cleaning protocols, may have contributed towards reducing contamination in these shared environments (Ryan et al., 20II).

To limit contact with bodily fluids including sweat, saliva and contaminants on hands, gym users are actively encouraged to clean equipment after use. Guidance includes using a towel as a barrier between surfaces and the body, not sharing towels or drink bottles, and washing hands before and after a gym session; these protocols are part of the standard guidelines for personal protection in gyms (Health Protection Agency, 20 I0). While Ryan et al. (20II) point to the potential effectiveness of these measures, there have been no studies to investigate these or other measures to limit infectious disease spread in the gym environment. In their research investigating the healthcare setting, White et al. (2015) found individual strategies to improve standard infection control measures, e.g., hand hygiene, should be used to specifically address healthcare workers' failure to implement protocols due to being distracted by role demands; for gym users this distraction could be their exercise routine. Ryan et al. (20II) suggest that attitude and behaviour may play a role in reducing the risk of contamination in a shared gym setting. 
This perspective is shared by White and colleagues (2015) who discuss how intention, as described in the theory of planned behavior (TPB), is the best predictor of an individual's attitude and actions (Ajzen, 1985). This theory can be related to infection control practices. Personal awareness of risk provides an important line of defence against infection and presents an opportunity to adopt preventative and protective measures. However, according to the TPB, as described below, engaging in practices that align with infection risk mitigation in gyms may involve a complex interplay of factors, that could be beyond the control of the individual gym user.

\section{THE THEORY OF PLANNED BEHAVIOUR}

The Theory of Planned Behaviour (TPB) first proposed by Ajzen (1985), has been shown to be useful in explaining the uptake of infection prevention and control measures. The theory suggests that an individual's intention to accomplish a behaviour is contingent upon a range of factors associated with their beliefs, ability to have control over an endeavour, and their consideration of the perceptions of others in terms of the importance of carrying out a behaviour (Ajzen, 1985). O'Connor's (2018) representation of this theory indicates that behavioural control plays an important direct role in an individual's behaviour and influences the intention to act, or perform a behavior.

The interplay between individuals' attitudes, the perceptions of others and the level of an individual's perceived control as indicated in the TPB, may help influence users' adoption of infection prevention techniques, and their compliance with infection prevention guidelines, when applied in the gym setting. The mode of transmission of CA-MRSA in a gym occurs via infected users who contaminate surfaces and equipment (CDC 2008). Therefore, promoting primary measures of prevention including educating gym users about infection spread, increasing personal hygiene measures including hand hygiene, and a robust cleaning schedule of building and equipment surfaces, can lessen or eliminate harmful pathogens (Redziniak et al., 2009). Studies have shown that it is possible to remove pathogens in gyms and sporting facilities through processes that support cleaner environments (Montgomery et al., 20I0; Ryan et al., 201 I). Elba and lvy (2018) found that signage, and easy access to cleaning equipment, led to an increase in post-use cleaning of gym equipment by users, most noticeably near signs prompting this behaviour. This study highlights that the prevention or reduction of contamination and infection risk in the shared 'island' spaces of gyms is possible when the TPB (Ajzen, 1985) is applied.

\section{THE RESEARCH STUDY: WHAT WERE THE RESEARCH QUESTIONS?}

This pilot study was undertaken to explore gym user behaviours relating to infection risk management. The study focused on answering two questions:

I. How aware are local gym users about infection risks in fitness centre settings?

2. What strategies do local gym users implement to reduce the chance of infection in fitness centre settings?

A number of areas were explored in this study; this article will report on the findings of two: gym users' awareness of infection risk and two strategies of the examined, user hand hygiene practices during gym visits and their postuse cleaning of equipment. In this study, gym users' hygiene practices were also considered to relate to the use of a personal towel, and hydration during a gym session.

\section{METHODS}

An online cross-sectional opt-in survey of gym users was conducted to gather quantitative data regarding users' beliefs and behaviours concerning infection risk management in the fitness centre setting. The survey questioned respondents to determine their awareness of infection risks, and to find out what strategies users believed would reduce the chance of infection. 
The wording of the pilot study questions was developed with the assistance of the Toi-Ohomai Research office staff, who peer reviewed the survey items, providing feedback on the content and complexity of the questionnaire. Ethical approval was provided by the Toi Ohomai Research committee (TRC 2018.060).

The survey was advertised online via social media, and to increase the number of participants in the study, 12 local gyms were asked if they could host recruitment advertisements including posters and flyers to be displayed at their facilities. Eight of the 12 local gyms (67\%) agreed to this. Therefore, participants of the study were gym users based in Rotorua and surrounding areas. Non-probability sampling (convenience sampling) was used to recruit participants. The study surveyed participants who were at least 18 years old and held a paid gym membership.

Google Forms, a free online survey website, was used to administer the survey. The front page of the survey contained an information sheet and statements about informed consent. Therefore, participants were required to complete the consent page before progressing to the actual survey questions.

The first section of the survey collected participant demographics and then asked three questions probing gym use, routines and regularity of attendance. The second part of the survey consisted of an eight-item questionnaire; items were based on a four-point Likert-type scale with accompanying subscales of between two and four items probing general knowledge of infection risk and understanding of infection control strategies. All questions were analysed using Microsoft Excel.

\section{RESULTS}

Convenience sampling recruited 55 participants aged 18 years or older from Rotorua and the surrounding areas, online and via the advertising on display in eight gyms. The majority of participants (80\%) were aged between 18 and 44 years (Table I), with more females than males responding to the survey (Table 2).

Table I. Survey Participants by Age Group

\begin{tabular}{|c|c|c|}
\hline Age Range & $\mathbf{n}$ & Percentage \\
\hline $\mathbf{1 8 - 2 4}$ & 9 & $16 \%$ \\
\hline $\mathbf{2 5 - 3 4}$ & 24 & $44 \%$ \\
\hline $\mathbf{3 5 - 4 4}$ & 11 & $20 \%$ \\
\hline $\mathbf{4 5 - 5 4}$ & 6 & $11 \%$ \\
\hline $\mathbf{5 5 - 6 4}$ & 4 & $7 \%$ \\
\hline $\mathbf{6 5 +}$ & 1 & $2 \%$ \\
\hline TOTAL & 55 & $100 \%$ \\
\hline
\end{tabular}

Table 2. Survey Participants by Gender

\begin{tabular}{|c|c|c|}
\hline Gender & $\boldsymbol{n}$ & Percentage \\
\hline Male & 21 & $38 \%$ \\
\hline Female & 34 & $62 \%$ \\
\hline TOTAL & 55 & $100 \%$ \\
\hline
\end{tabular}




\section{Gym Activities Among Participants}

All participants were active gym users, with $71 \%$ attending the gym three or more times a week. The most popular gym activities among participants were cardiovascular exercises (76\%) followed by weight and resistance training (58\%) with fewer undertaking class or group-based routines (24\%). Many of the participants in this sample maintained a varied programme while visiting the gym with over half the respondents (56.4\%) completing more than one activity; of these $47.3 \%$ engaged in two areas of exercise or training and $9 \%$ engaged in three or more activities.

Table 3. Participants by Type of Gym Use

\begin{tabular}{|c|c|}
\hline Gym Activity Participation & Percentage \\
\hline Cardiovascular exercise & $76 \%$ \\
\hline Weight/resistance training & $58 \%$ \\
\hline Class/group routines & $25 \%$ \\
\hline Other & $6 \%$ \\
\hline
\end{tabular}

\section{Awareness of Infection Risk in the Gym}

\section{Infection risk awareness in gyms}

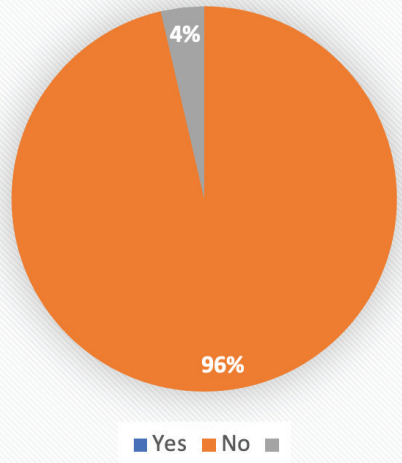

Figure I. Infection Risk Awareness

Participants were asked to report on their awareness of the gym as a potential reservoir of infectious agents which could lead to infection. Surprisingly, $97 \%$ of survey respondents (Figure I) demonstrated awareness that gyms can harbour contaminates which can act as a source of infection. The survey did not explore factors that may have influenced their understanding and awareness, consequently it is not clear why this group was so aware of the potential risk of infection. Level of education and age (less than 40 years) are shown to be two key factors influencing health literacy; health literacy and prior knowledge are, in turn, identified as determinants of health behaviour (Sun et al., 2013). While the educational background of participants was not explored, $80 \%$ of participants were 44 years or younger, hence age may be related to increased infection awareness in this study. 


\section{Hand Hygiene}

The study was undertaken prior to the global Covid-19 pandemic, when hand washing received less attention and hand sanitiser use in public areas was not as apparent, nor were these widely promoted as public health measures. In the survey, 'hand washing' was used as a generic and familiar term in items which aimed to establish hand hygiene practices among the gym users. Participants in this pilot study appeared to demonstrate good adherence to recommended hand hygiene practice guidelines for gym users (Dalton et al., 2020). Users were more conscious of their hand hygiene practice while in the gym, with 32\% reporting they were 'always' and 60\% 'sometimes' compliant with the practice (Figure 2). However, the results show there is room for improvement, with few participants using hand hygiene as a protective mechanism. Good hand hygiene prior to and after gym use reduces microbial colonisation of areas and avoids transmission of contaminates into the community. In the 'COVID-19' era, public awareness of the importance of hand hygiene has increased, as has the availability of hand sanitiser, including users carrying their own, so if this study was to be carried out now, the survey may produce different results.

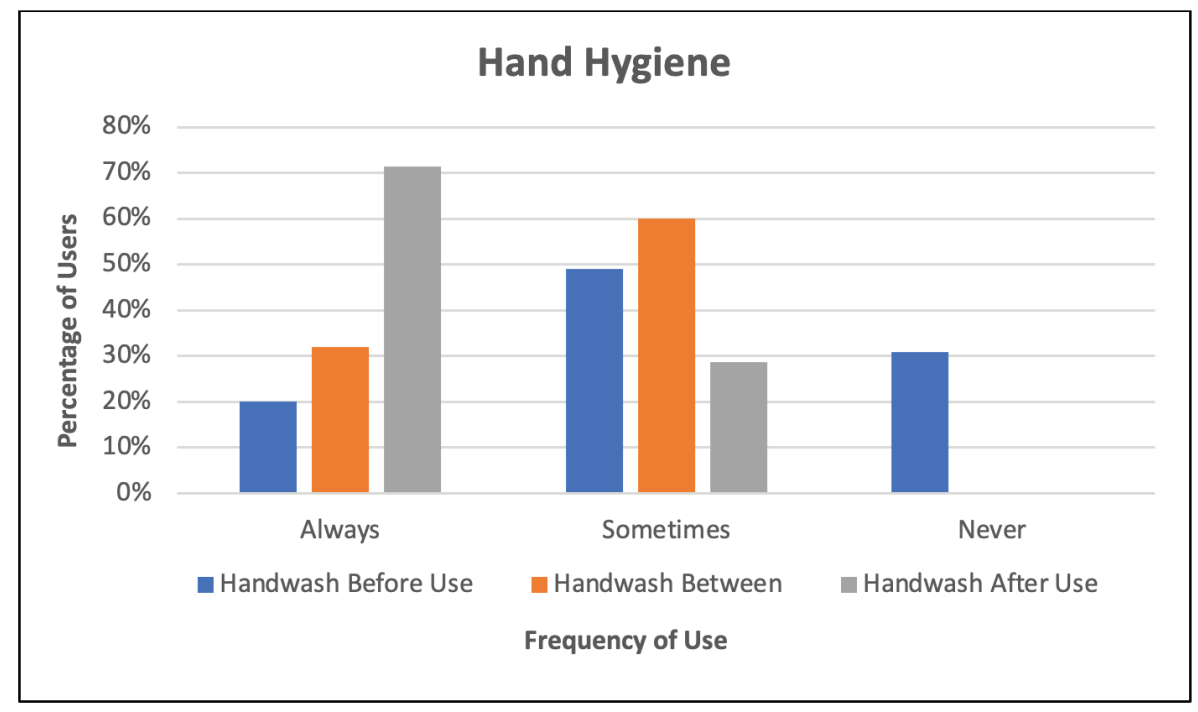

Figure 2. Hand Hygiene Practices Among Gym Users

When comparing hand hygiene practice among male and female gym user groups, the study found that female users tended to be more diligent with their hand hygiene practice before and during gym use, and less likely to avoid cleaning their hands when actively involved at the gym compared with male gym users. Female gym users did report a tendency to ignore hand hygiene when leaving the gym, however this difference was not statistically significant (Table 4). 
Table 4. Hand Hygiene Practice by Occasion and Gender

\begin{tabular}{|c|c|c|c|}
\hline \multicolumn{5}{|c|}{ Before } \\
\hline & $\begin{array}{c}\text { Always } \\
\text { (Percentage) }\end{array}$ & $\begin{array}{c}\text { Sometimes } \\
\boldsymbol{n} \text { (Percentage) }\end{array}$ & $\begin{array}{c}\text { Never } \\
\boldsymbol{n} \text { (Percentage) }\end{array}$ \\
\hline Male & $3(14.3 \%)$ & $10(47.6 \%)$ & $8(38.1 \%)$ \\
\hline Female & $8(23.5 \%)$ & $17(50 \%)$ & $13(26.5 \%)$ \\
\hline Male & $3(14.3 \%)$ & $5(23.8 \%)$ & $17(50 \%)$ \\
\hline Female & $5(14.7 \%)$ & $10(31.3 \%) *$ & $1(4.8 \%)$ \\
\hline Male & $13(61.9 \%)$ & $4(19.1 \%)$ & $5(14.7 \%)$ \\
\hline Female & $22(64.7 \%)$ & $10(29.4 \%)$ & \\
\hline
\end{tabular}

* Two did not respond, \% has been calculated based on $32 / 34$ respondents

When comparing the overall hand hygiene practices (always and sometimes) reported by gym users by gender (within group comparison) females' use of hand hygiene (73.5\%) exceeded that of males on each occasion of use; (Before: 61.9\%, Between: $34.41 \%$ and After: $51.41 \%$, within group comparison), as depicted in Table 5.

Table 5. Overall Hand Hygiene Practice by Gender

\begin{tabular}{|c|c|c|}
\hline \multicolumn{2}{|c|}{ Hand Hygiene Practice: Always and Sometimes; Before, Between and After, by Gender } \\
\hline & $\begin{array}{c}\text { Before } \\
\%\end{array}$ & $\begin{array}{c}\text { Total Participants } \\
\%\end{array}$ \\
\hline Male & $61.90 \%(n=21)$ & $23.64 \%(n=55)$ \\
\hline Female & $73.53 \%(n=34)$ & $45.45 \%(n=55)$ \\
\hline & $\begin{array}{c}\text { Between } \\
\%\end{array}$ & $\begin{array}{c}\text { Total Participants } \\
\%\end{array}$ \\
\hline Male & $26.81 \%(n=21)$ & $12.09(n=55)$ \\
\hline Female* & $34.41 \%(n=32)$ & $23.87(n=53)$ \\
\hline & After & Total Participants \\
$\%$
\end{tabular}

* Two female participants did not respond, \% has been calculated based on 53/55 respondents

However, when a chi-square test of independence was undertaken to investigate the relationship between gender and hand hygiene before and after gym use, a different pattern was revealed. The relationship between the gender and hand hygiene variables was shown to be significant: males $x^{2}(1, n=20)=14.1186, p=<.001$, (000859), $p$ $<.05$, compared with females $x^{2}(I, n=33)=4.9126, p=>.05,(.085753), p<.05$. Therefore, males undertook hand hygiene practices after gym use significantly more often than females. 
Table 6. Overall Combined Hand Hygiene Practice by Users by Occasion

\begin{tabular}{|c|c|c|c|}
\hline Totals & $\begin{array}{c}\text { Always } \\
\boldsymbol{n}\end{array}$ & $\begin{array}{c}\text { Sometimes } \\
\boldsymbol{n}\end{array}$ & $\begin{array}{c}\text { Total Combined } \\
\text { (Always \& Sometimes) } \\
\%\end{array}$ \\
\hline Before & 11 & 27 & 60.1 \\
\hline Between & 8 & 15 & 35.3 \\
\hline After & 35 & 14 & 60.5 \\
\hline
\end{tabular}

The overall analysis of gym users' hand hygiene practices before, during, and after gym use, shows that over half of all users made some effort to complete hand hygiene before (60.1\%) and after (60.5\%). Participants showed less awareness of hand hygiene while moving between equipment or changing routines.

Table 7. Hand Hygiene Practice by Age Group

\begin{tabular}{|c|c|c|c|}
\hline \multicolumn{4}{|c|}{ Before } \\
\hline & $\begin{array}{c}\text { Always } \\
n \text { (Percentage) }\end{array}$ & $\begin{array}{c}\text { Sometimes } \\
n \text { (Percentage) }\end{array}$ & $\begin{array}{c}\text { Never } \\
n \text { (Percentage) }\end{array}$ \\
\hline $18-24$ & $3(33.3 \%)$ & $4(44.4 \%)$ & $2(22.2 \%)$ \\
\hline $25-34$ & $4(16.7 \%)$ & $14(58.3 \%)$ & $6(25 \%)$ \\
\hline $35-44$ & $2(18.2 \%)$ & $5(45.5 \%)$ & $4(36.4 \%)$ \\
\hline $45-54$ & $2(33.3 \%)$ & $3(50 \%)$ & I (16.7\%) \\
\hline $55-64$ & 0 & । (25\%) & $3(75 \%)$ \\
\hline $65+$ & 0 & 0 & I (I00\%) \\
\hline \multicolumn{4}{|c|}{ Between } \\
\hline $18-24$ & $3(33.3 \%)$ & $2(22.2 \%)$ & $4(44.4 \%)$ \\
\hline 25-34* & $3(13 \%)$ & $8(34.8 \%)$ & $12(52.2 \%)$ \\
\hline 35-44*** & 0 & $4(40 \%)$ & $6(60 \%)$ \\
\hline $45-54$ & I (16.7\%) & I (I6.7\%) & $4(66.7 \%)$ \\
\hline $55-64$ & I (25\%) & 0 & $3((75 \%)$ \\
\hline $65+$ & 0 & 0 & I (I00\%) \\
\hline \multicolumn{4}{|c|}{ After } \\
\hline $18-24$ & $8(88.9 \%)$ & 0 & I (II.1\%) \\
\hline $25-34$ & $12(50 \%)$ & 9 (37.5\%) & $3(12.3 \%)$ \\
\hline $35-44$ & $8(72.7 \%)$ & $3(27.3 \%)$ & 0 \\
\hline $45-54$ & $5(83.3 \%)$ & 0 & I (I6.7\%) \\
\hline $55-64$ & $2(50 \%)$ & I (25\%) & I (25\%) \\
\hline $65+$ & 0 & I (100\%) & 0 \\
\hline
\end{tabular}

* One 25-34-year-old did not respond, \% calculated based on 23/24 respondents

** One 34-44-year-old did not respond, \% calculated based on 10/1I respondents 
An analysis of hand hygiene practice by age was undertaken to identify whether hygiene practices varied during gym attendance across the selected age groups. In this study, more consistent hand hygiene practice (always or sometimes) during gym sessions was observed among those who were somewhat older. However, overall, advancing age is seen to more commonly be associated with the lack of hand hygiene during a gym visit. It remains unclear whether the observed lack of engagement with hand hygiene practices among older users in this study, reflects a lack of awareness of infection-related risks associated with gym use among older people in the preCOVID-19 environment. Due to the small number of participants in each group, no further analysis to evaluate age-related hygiene practices was undertaken. Further investigation of the general awareness of infection risk among the population of older, potentially more vulnerable, gym users is warranted.

\section{Use of Gym Cleaning Products}

Figure 3 illustrates the frequency of use of gym cleaning products among participants. A similar percentage of participants wiped equipment always, or sometimes, before use ( $93 \%$ in total) as compared to always, or sometimes, wiping equipment after use ( $94 \%$ in total). However, on further investigation, the number of people who always wiped equipment before use was significantly lower $(p<0.05)$ than those who wiped it after use.

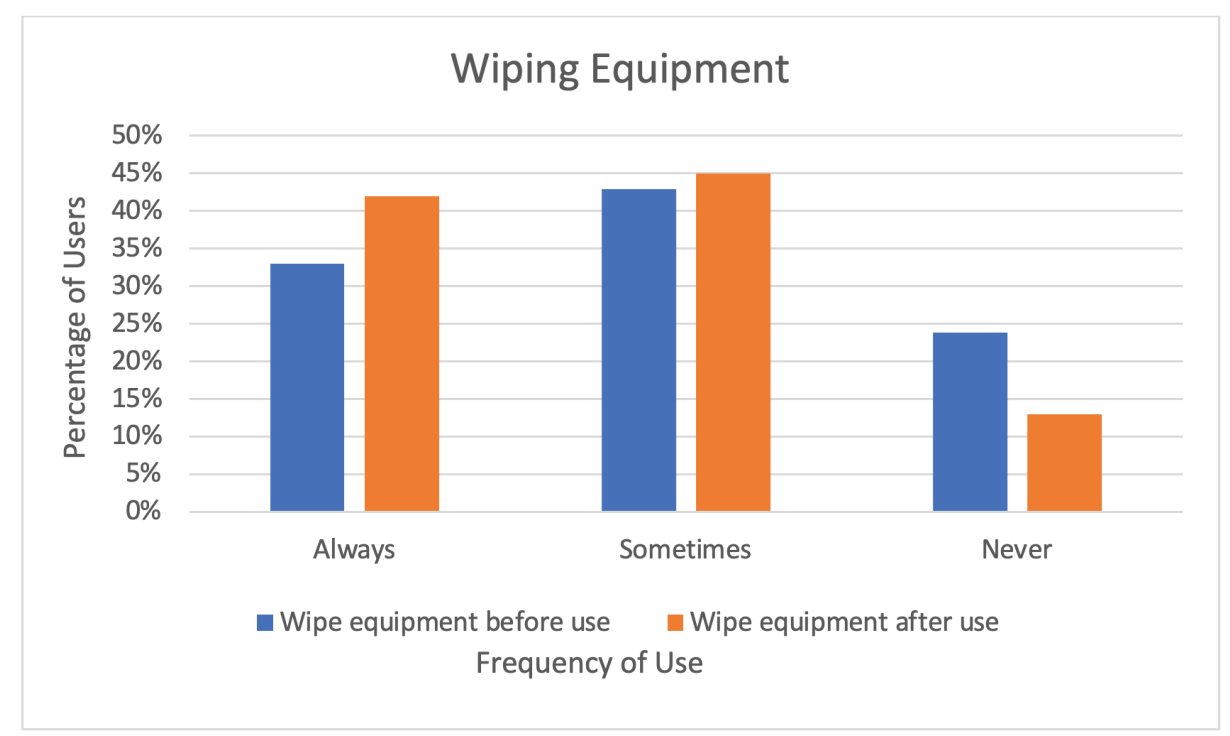

Figure 3. Frequency of Wiping of Gym Equipment 
Table 8. Equipment Cleaning by Gender

\begin{tabular}{|c|c|c|c|}
\hline \multicolumn{5}{|c|}{ Before } \\
\hline & $\begin{array}{c}\text { Always } \\
\text { (Percentage) }\end{array}$ & $\begin{array}{c}\text { Sometimes } \\
\boldsymbol{n} \text { (Percentage) }\end{array}$ & $\begin{array}{c}\text { Never } \\
\text { (Percentage) }\end{array}$ \\
\hline Male & $7(33.3 \%)$ & $9(42.9 \%)$ & $5(23.8 \%)$ \\
\hline Female* & $13(41.9 \%) *$ & $14(45.2 \%) *$ & $4(12.9 \%)$ \\
\hline \multicolumn{4}{|c|}{ After } \\
\hline Male & $8(38.1 \%)$ & $11(52.4 \%)$ & $2(9.5 \%)$ \\
\hline Female* & $18(52.9 \%) *$ & $11(32.4 \%) *$ & $2(5.9 \%)$ \\
\hline
\end{tabular}

*Three female participants did not respond, \% calculated based on 31 respondents

Consistent wiping of equipment (always) before use, appears lower than after use for both male and female users (Table 7). Occasional cleaning of equipment appears slightly higher; however, the three female participants who failed to respond to this section of the survey have limited the analysis and comparison. As a group, females wipe equipment (always and sometimes) before use more often than males do, while males appear more diligent with this practice after equipment use in general, (Table 8). The results indicate that the wiping of equipment before and after use as a precautionary decontamination measure may not be strong among this group of participants. It is concerning that some users report they do not wipe down equipment during gym sessions. These findings suggest that education of gym users is required to increase their awareness and practice of gym hygiene to protect themselves and other users by reducing microbial colonisation levels and contamination of shared gym equipment.

Table 9. Overall Equipment Cleaning by Gender

\begin{tabular}{|c|c|c|}
\hline \multicolumn{3}{|c|}{ Equipment Cleaning by Gender } \\
\hline & $\begin{array}{c}\text { Before } \\
\boldsymbol{n} \text { (Percentage) }\end{array}$ & $\begin{array}{c}\text { After } \\
\boldsymbol{n} \text { (Percentage) }\end{array}$ \\
\hline Male & $49.86(n=21)$ & $60.38(n=21)$ \\
\hline Female* & $58.16(n=31)$ & $53.48(n=31)$ \\
\hline
\end{tabular}

* Three female participants did not respond to this question 
Table 10. Equipment Cleaning by Age

\begin{tabular}{|c|c|c|c|}
\hline \multicolumn{4}{|c|}{ Before } \\
\hline & $\begin{array}{c}\text { Always } \\
n \text { (Percentage) }\end{array}$ & $\begin{array}{c}\text { Sometimes } \\
\text { n (Percentage) }\end{array}$ & $\begin{array}{c}\text { Never } \\
n \text { (Percentage) }\end{array}$ \\
\hline 18-24* & $4(50 \%)$ & $4(50 \%)$ & 0 \\
\hline 25-34*** & $10(43.5 \%)$ & II (47.8\%) & 2 (8.7\%) \\
\hline 35-44***** & $2(20 \%)$ & 5 (50\%) & $3(30 \%)$ \\
\hline $45-54$ & $2(33.3 \%)$ & $2(33.3 \%)$ & $2(33.3 \%)$ \\
\hline $55-64$ & $2(50 \%)$ & I (25\%) & I (25\%) \\
\hline $65+$ & 0 & 0 & I (I00\%) \\
\hline \multicolumn{4}{|c|}{ After } \\
\hline 18-24* & $4(50 \%)$ & $4(50 \%)$ & 0 \\
\hline $25-34 * *$ & $10(43.5 \%)$ & $10(43.5 \%)$ & $3(13 \%)$ \\
\hline 35-44**** & $4(40 \%)$ & $5(50 \%)$ & I (I0\%) \\
\hline $45-54$ & $4(66.7 \%)$ & $2(33.3 \%)$ & 0 \\
\hline $55-64$ & $3(66.7 \%$ & I (25\%) & 0 \\
\hline $65+$ & I (75\%) & 0 & 0 \\
\hline
\end{tabular}

* One 18-24-year-old participant did not respond, \% calculated based on 8/9 respondents

*** Two 25-35 -year-old participants did not respond, \% calculated based on 23/24 respondents

*** Three 35-44-year-old participants did not respond, \% calculated based on 10/II respondents

An analysis of post use cleaning of equipment by age shows a similar pattern of results as for hand hygiene practices. Generally younger gym users more consistently (always), or occasionally (sometimes), wipe equipment before and after use compared with older users (Table 9). However, when overall post use equipment cleaning (always and sometimes) is combined across each age group (Table 10), younger gym users appear to demonstrate more frequent practice that those who are middle aged and older. Again, due to the smaller age group sizes and the failure of several participants to respond to this section of the study, no further analysis was undertaken. Thus, it is not clear why older participants were less inclined to wipe equipment when using the gym. Further research is required to assess whether this finding points to less awareness or understanding of the risk of infections posed by gym use among older gym users. This research result might change if the survey was carried out now, due to publicity about infection spread in the COVID-19 climate. Increased infection risk general awareness since the onset of COVID-19 may translate to high levels of surface cleaning by gym users during gym visits. 
Table II. Equipment Cleaning by Age Group

\begin{tabular}{|c|c|c|}
\hline \multicolumn{3}{|c|}{ Equipment Cleaning by Age Group } \\
\hline Age Groups & $\begin{array}{c}\text { Always and Sometimes } \\
\text { by Age Group } \\
\text { (Percentage) }\end{array}$ & $\begin{array}{c}\text { Always and Sometimes } \\
\text { Total Respondents } \\
\text { (Percentage) }\end{array}$ \\
\hline $18-24 *$ & 54.0 & $4.0(n=54)$ \\
\hline $25-34 *$ & 57.8 & $14.7(n=54)$ \\
\hline $35-44 *$ & 52.0 & $10.6(n=54)$ \\
\hline $45-54$ & 35.3 & $5.6(n=55)$ \\
\hline $55-64$ & 27.0 & $2.8(n=55)$ \\
\hline $65+$ & 0.0 & $1.8(n=55)$ \\
\hline
\end{tabular}

* One participant in each of the identified age groups did not respond, \% has been calculated based on 54/55 respondents

\section{DISCUSSION}

\section{Variability of Hygiene Practices}

There is a high level of awareness among study participants of infection risks in gyms related to hand hygiene practices and wiping of equipment either always or sometimes, before and after a visit to the gym. However, inconsistencies in gym hygiene practices are apparent among males and females and across various ages groups, for example, hand hygiene measures are less frequently practised between use of gym equipment during a gym session. A lack of awareness and variable use of hygiene practices and self-protection measures among gym users are a potential infection risk, as soft tissue infections or a disease outbreak may occur. Female users, in general, appeared to be more consistent in their hand hygiene practice while there appeared to be awareness across all age groups about the need for hand hygiene practice after completing a programme of exercise/before leaving the gym. In this study, participants demonstrated more consistent use of hand hygiene measures after gym use, a finding that aligns with research investigating health professionals' hand hygiene practices (Fouad \& Eltaher, 2020); higher rates of hand hygiene compliance were seen among health staff after patient care than before. Various strategies are employed to increase hand hygiene compliance rates in healthcare settings, however variable compliance with hand hygiene practices remains a persistent challenge in health care.

A longitudinal study of hand hygiene compliance among health care professionals in an acute health care setting illustrates this challenge. After direct observation and feedback strategies were implemented, hand hygiene compliance among the studied group increased over a five-year period from $76.4 \%$ to $88.5 \%$ (Ojanperä et al., 2020). Hand hygiene is promoted in health care settings due to the ever-present threat of hospital acquired infections and the recognition that hand hygiene is a critical decontamination approach in controlling the spread of nosocomial infections (World Health Organisation, 2002).

\section{Awareness of Infection Risk}

The results of the survey of 55 participants at local gyms in Rotorua showed a significant level of awareness of the risk of infection present in a gym and of the benefits of adhering to hand hygiene measures during a gym visit. More than $60 \%$ of survey respondents reported use of hand hygiene measures, indicating a baseline of personal awareness. Promotional measures such as posters displayed in gyms, remind users about the need for hygiene practices; these have been shown to translate hand hygiene intention into action in a gym setting (Elba \& Ivy, 20।8) and may have an important impact on improving communal spread of infection beyond the gym. 


\section{Wiping Equipment to Reduce Infection Risk}

While over half of the participants in this study reported wiping equipment at some point during a gym visit, more consistent use among users would contribute towards reduced colonies of microorganisms on gym surfaces, and limit or eliminate subsequent transmission among users. When surface cleaning is undertaken to remove organic material and accompanied by disinfection, contamination load is reduced along with the risk of transmission (Assadian et al., 2021). A study comparing rates of MRSA contamination of health workers gloved hands following skin contact, and contact with common environmental surfaces in patient isolation rooms, found similar colonisation levels (40-45\%) from both sources (Stiefel et al., 20II), highlighting that surfaces are a key source of contamination. Daily disinfection of high touch surfaces in a hospital setting contributes to a significant reduction in microbial colonisation found on the hands of health care workers who have regular contact with the surfaces (Kundrapu et al., 2012). When the aim of cleaning is to reduce the transmission of infection, the choice of disinfection method is important. In a hospital environment applying disinfectant spray to surfaces is effective in reducing colonisation but the extended drying time is a disadvantage in high contact areas (Rutala et al., 20 I2). However, wiping using pre-saturated disposable disinfectant wipes produces a significant reduction in surface contamination and microbial transmission, with the added advantage of reduced drying times, leader to better protection against infection risk (Rutala et al., 2012; Rutala \& Weber, 2016).

As well as users adopting responsibility for equipment wiping following use, the Centers for Disease Control and Prevention (2019) recommend a programme of equipment and surface decontamination for gym facilities, to reduce infection spread through skin contact. Chlorine has been identified as an ideal disinfectant for use at appropriate dilutions to reduce CA-MRSA transmission through skin contact in a gym (Grindle et al., 2014). The need for a rigorous cleaning programme has been highlighted by increased demand for and use of gym and fitness facilities by the travelling public in the hotel industry. Infection outbreaks amongst hotel guests have been tracked to high touch equipment surfaces; this has led to calls for relevant policies to be developed, and special attention being given to surface cleaning by patrons and household staff to prevent when seeking to reduce the transmission of infection the spread of contaminants in hotels (Kravitz, 20I2).

\section{Promoting Behaviour Change}

Governments across the globe have been making efforts to minimise the spread of infectious diseases by promoting individual behaviour change and interventions that include building awareness among the general population and encouraging protective behaviors such as hand washing and social distancing (World Health Organisation, 202I). Population behaviour plays an important role in determining the success of these preventive measures, specifically social distancing and handwashing, during a pandemic (Centers for Disease Prevention and Control, 202lb). However, these same measures are promoted as sound advice for the general public to prevent infection spread in shared spaces such as schools and workplaces (Ministry of Health, 2021).

Therefore, the gym user population of gym should receive specific messaging appropriate to this community 'island' space. The study results indicate that people's behaviour and awareness of their risk of becoming infected from equipment and surfaces in a shared exercise facility varies, and is related to their age. Use of hand hygiene between use of equipment during a workout was rare.

\section{LIMITATIONS}

As members of participating gyms, survey respondents may have been more conscious of the risk of infection and more likely to use hygiene strategies due to increased awareness generated by promotion of infection control practices. N.B., this study differentiated between gym users who may have been employees and those who were enrolled members. 


\section{PRACTICAL APPLICATIONS}

- Many gym users have some awareness of infection risk in gyms, but this study found gym members were inconsistent in using hygiene practices designed to decontaminate surfaces and minimise transmission of the pathogens commonly found in gyms. Therefore, it is recommended that gym owners and staff take responsibility for regular cleaning of equipment and surfaces in gyms.

- Awareness of infection risk among gym user was high, therefore education to promote hygiene practices should be well received.

- $\quad$ Enhanced hygiene practices among gym users may be contingent upon ready access to hand hygiene products for regular hand sanitisation, and upon the availability of disposable disinfectant wipes for cleaning equipment.

- A range of prompts including signage throughout the gym may reinforce awareness and prompt gym users to implement hygiene practices, actively contributing to greater decontamination of high contact surfaces.

- With increasing rates of CA-MRSA reported in the community in general (Williamson et al., 20I3), and in gym and fitness centres (Braun \& Kahanov, 2018), more proactive measures by both gym owners and users are required to limit spread in this high surface contact environment.

- Gyms should specifically encourage the wiping down of equipment before use.

\section{FUTURE DIRECTIONS}

Future studies should investigate how public health pandemic messaging has affected hygiene awareness and practices in gyms, i.e., researchers should explore how pandemic-related messaging might have increased infection transmission awareness and altered users' hygiene-enhancing behaviours. Future researchers should aim to recruit larger numbers of participants, and also consider their computer access or digital literacy, if an online survey method is used.

Future research could be undertaken to investigate the specific microbial ecology of gym surfaces in New Zealand by growing cultures from swabs taken from gym surfaces. This may establish the infection risks and transmission patterns specific to the New Zealand gym and fitness centre context.

Researchers could consider exploring the effects of infection risk education programmes for older gym users, who are increasing in number as the population ages and the benefits of physical fitness for older adults become more widely known.

Finally, it would be of interest to understand gym users' hygiene-related habits in the context of COVID-19 to determine the effects of the pandemic on hygiene practices in gyms.

\section{CONCLUSION}

Hygiene education in the past has focused on wiping equipment to clean it after use. But disease spread is increasing, and individuals are now undertaking infection risk management precautions such as limiting contact through social distancing and using PPE and masks to protect personal 'bubbles'. Therefore, gyms should ensure that messaging about wiping down equipment before and after use, focuses on before use cleaning, to limit the spread of infectious diseases. This study also highlights the general need for increased awareness of, and compliance with hand hygiene and decontamination strategies in gyms, which should be promoted and practised in similar ways as in healthcare settings. Lastly, as gyms are considered high-density environments, i.e., they are warm and humid, gym users who are unwell should be actively discouraged from visiting the gym. The elimination of infectious diseases in New Zealand (an island nation) has been very successful, and therefore as gyms are 'islands', this approach should be highly effective. 


\section{FUNDING AND ACKNOWLEDGMENTS}

This research was funded by the Toi Ohomai Institute of Technology School of Research though a student summer scholarship. The authors would like to thank the School of Research for the funding for the research assistant associated with this project $(\$ 5,000)$.

Rolyn Sullano, as the research assistant, was responsible for the data collection and the promotion of this research over the summer of 2018/2019, the authors would like to thank him for his valuable contribution.

Mary Cooper (10 https://orcid.org/0000-0002-7029-9103 is a senior lecturer within the Health Department at Toi Ohomai Institute of Technology, leading programmes in infection risk management and health, with a research focus in infection risk management and sterilisation sciences. Mary was part of the development team for the Diploma in Sterilising Technology and has taught on the programme since its inception in 2019.

Pavitra Dhamija (1D) https://orcid.org/0000-0001-5882-1/68 is a senior academic staff member at Toi Ohomai Institute of Technology, with research interests in infection risk management. Pavi is currently teaching on the New Zealand diploma in sterilisation technology and has a leadership role in the sterilisation suite of programmes.

Elizabeth Youard (10) https://orcid.org/0000-0001-8784-0579 is a senior academic staff member at Toi Ohomai Institute of Technology, with research interests in health and wellbeing and education. She is in the process of gaining her Masters with a focus on online education. Elizabeth has previously taught on the infection risk management programme.

Campbell Macgregor (10) https://orcid.org/0000-000 I-6161-8945: Ko Tākitimu, ko Hananui kā mauka, Ko Kāi Tahu kā iwi and is a principal lecturer and academic lead - health at Toi Ohomai Institute of Technology with an interest in incorporating Mātauranga Māori and cultural responsiveness. Campbell has managed gyms in New Zealand and Australia. Furthermore, he is active in research in the bone health of older athletes, and indigenous solutions. Campbell, was identified by the American College of Sports Medicine, as their 2013 International Clinical Scholar.

Correspondence to: Campbell Macgregor, 70 Windermere Dr, Tauranga, 3112

Email: Campbell.macgregor@toiohomai.ac.nz

\section{REFERENCES}

Ajzen, I. (1985). From intentions to actions: A theory of planned behaviour. In J. Kuhl \& J. Beckman (Eds.), Action control: From cognition to behaviour. Springer-Verlag.

Andrade, A., Dominski, F. H., Pereira, M. L., de Liz, C. M., \& Buonanno, G. (2018). Infection risk in gyms during physical exercise. Environmental Science \& Pollution Research, 25(20), 19675-19686. https://doi.org/10.1007/s| I356-018-1822-8

Assadian, O., Harbarth, S., Vos, M., Knobloch, J. K., Asensio, A., \& Widmer, A. F. (2021). Practical recommendations for routine cleaning and disinfection procedures in healthcare institutions: A narrative review. Journal of Hospital Infection, 1/3, I04-114. https://doi.org/10.1016/j.jhin.2021.03.010

Australasian Leisure Management. (2021). Fitness/wellness. https://www.ausleisure.com.au/news/new-zealand-set-for-massivewellness-growth/

Bilung, L. M., Tahar, A. S., Kira, R., Mohd Rozali, A. A., \& Apun, K. (2018, 01 / 0I /). High occurrence of Staphylococcus aureus isolated from fitness equipment from selected symnasiums [Article]. Journal of Environmental and Public Health, $2018,1-5$. https://doi.org/l0.1155/2018/4592830 
Braun, T. I. M., \& Kahanov, L. (2018). Community-associated methicillin-resistant Staphylococcus aureus infection rates and management among student-athletes. Medicine \& Science in Sports \& Exercise, 50(9), 1802-1809. https://doi.org/I0.1249/ MSS.0000000000001649

Centers for Disease Control and Prevention. (2019). Athletic facilities: Cleaning and disinfecting. https://www.cdc.gov/mrsa/ community/environment/athletic-facilities.html?CDC_AA_refVal=https\%3A\%2F\%2Fwww.cdc.gov\%2Fmrsa\%2Fcommuni ty\%2Fenviroment\%2Fathletic-facilities.html

Centers for Disease Prevention and Control. (202lb). COVID-19: How to protect yourself and others. https://www.cdc.gov/ coronavirus/2019-ncov/prevent-getting-sick/prevention.html

Cohen, P. R. (2008). The skin in the gym: A comprehensive review of the cutaneous manifestations of community-acquired methicillin-resistant Staphylococcus aureus infection in athletes. Clinics in Dermatology, 26(1), 16-26. https://doi.org/l0.10 16/j. clindermatol.2007.10.006

Dalton, C., Katelaris, A., \& Wilson, N. (2020). Open with Care: Minimising COVID-19 Superspreading Settings in Australia. SSRN online. I-12. http://dx.doi.org//0.2139/ssrn.3625655

Desai, R., Pannaraj, P. S., Agopian, J., Sugar, C. A., Liu, G. Y., \& Miller, L. G. (20II). Survival and transmission of communityassociated methicillin-resistant Staphylococcus aureus from fomites. AllC: American Journal of Infection Control, 39(3), 219-225. https://doi.org/10.1016/j.ajic.2010.07.005

Elba, I., \& Ivy, J. W. (2018). Increasing the post-use cleaning of gym equipment using prompts and increased access to cleaning materials. Behavior Analysis in Practice, II (4), 390-394. https://doi.org/I0.1007/s40617-018-02 I7-0

Fouad, M., \& Eltaher, S. (2020). Hand hygiene initiative: Comparative study of pre- and postintervention outcomes. Eastern Mediterranean Health Journal, 26(2), 198-205. https://doi.org//0.26719/2020.26.2.198

Grindle, M., Games, K. E., Eberman, L. E., Kahanov, L., \& Caswell, S. (2014). Appropriate disinfection techniques for playing surfaces to prevent the transmission of bloodborne pathogens. International Journal of Athletic Therapy \& Training, 19(5), 12-15. https://doi.org//0.1123/ijatt.2014-0032

Health Protection Agency. (2010). Sports infection and prevention control guidance. https://www.biocote.com/wp-content/ uploads/2017/II/Health-Protection-Agency-North-West-Sports-Infection-Prevention-Control-Guidance-July-20I0.pdf

Junnila, J., Hirvioja, T., Rintala, E., Auranen, K., Rantakokko-Jalava, K., Silvola, J., Lindholm, L., Gröndahl-Yli-Hannuksela, K., Marttila, H., \& Vuopio, J. (2020). Changing epidemiology of methicillin-resistant Staphylococcus aureus in a low endemicity area new challenges for MRSA control. European Journal of Clinical Microbiology \& Infectious Diseases 39(I2), 2299-2307. https:// doi.org/10.1007/s10096-020-03824-9

Kravitz, R. (2012). Thinking outside the box to keep hotels clean and healthy. Executive Housekeeping Today, 34(10), 12-21. https://ezproxy.toiohomai.ac.nz/login?url=https://search.ebscohost.com/login.aspx?direct=true \&db=vlh\&AN=83238|38 \&site=eds-live

Kundrapu, S., Sunkesula, V., Jury, L. A., Sitzlar, B. M., \& Donskey, C. J. (2012). Daily disinfection of high-touch surfaces in isolation rooms to reduce contamination of healthcare workers' hands. Infection Control and Hospital Epidemiology, 33(I0). https://doi.org/http://www.jstor.org/stable/I0.1086/667730?origin=JSTOR-pdf

Lee, G., \& Bishop, P. (2016). Microbiology and infection control for health professionals (6th ed.). Pearson.

Loewen, K., Schreiber, Y., Kirlew, M., Bocking, N., \& Kelly, L. (2017). Community-associated methicillin-resistant Staphylococcus aureus infection: Literature review and clinical update. Canadian Family Physician/ Medecin de Famille Canadien, 63(7), 512-520. https://ezproxy.toiohomai.ac.nz/login?url=https://search.ebscohost.com/login.aspx?direct=true\&db=cmedm\&A $\mathrm{N}=2870 \mid 438$ \&site=eds-live

Meade, T. (2015). Disinfect the rec: Creating and implementing a disinfection campaign at gyms using the theory of planned behavior. Recreational Sports Journal, 39(2), I57-169. https://doi.org/http://dx.doi.Org/l0.1123/rsj.2015-0037

Ministry of Health. (2021). Prevent the spread of infectious disease. https://www.health.govt.nz/your-health/healthy-living/ environmental-health/infectious-disease-prevention-and-control/prevent-spread-infectious-disease

Montgomery, K., Ryan, T., Krause, A., \& Starkey, C. (2010). Assessment of athletic health care facility surfaces for MRSA in the secondary school setting. Journal of Environmental Health, 72(6), 8-11. https://doi.org/https://www.jstor.org/stable/26328056

Moriya, M., Tsurukiri, J., Nakaminami, H., Yamanaka, H., Kobayashi, T., Tsubouchi, N., Yokomori, R., Takadama, S., Noguchi, N., Matsumoto, T., \& Arai, T. (2020). A risk as an infection route: Nasal colonization of methicillin-resistant Staphylococcus aureus USA300 clone among contact sport athletes in Japan. Journal of Infection and Chemotherapy: Official Journal of the Japan Society of Chemotherapy, 26(8), 862-864. https://doi.org/I0.1016/j.jiac.2020.04.027

Mukherjee, N., Dowd, S. E., Wise, A., Kedia, S., Vohra, V., \& Banerjee, P. (2014). Diversity of Bacterial Communities of Fitness Center Surfaces in a U.S. Metropolitan Area of fitness center surfaces in a U.S. metropolitan area. International Journal of Environmental Research and Public Health, II(I2), |2544-I2561. https://doi.org/I0.3390/ijerph I I I212544 
New Zealand Institute of Health and Fitness. (2021). What makes up the New Zealand fitness industry? https://nzihf.ac.nz/personaltraining-careers/new-zealand-fitness-industry-overview/

Núñez-Corrales, S., \& Jakobsson, E. (2020). The epidemiology workbench: a tool for communities to strategize in response to COVID-19 and other infectious diseases. medRxiv.7, I-31 : https://doi.org/l0.1101/2020.07.22.20159798

O'Connor, R. (2018). Using exercise psychology: Theory of planned behaviour. https://absolutebalance.com.au/using-exercisepsychology-theory-of-planned-behaviourl

Ojanperä, H., Kanste, O. I., \& Syrjala, H. (2020). Hand-hygiene compliance by hospital staff and incidence of healthcare-associated infections, Finland. Cumplimiento de la higiene de las manos entre el personal de los hospitales y la incidencia de las infecciones relacionadas con la atención médica, Finlandia., 98(7), 475-483. https://doi.org/I0.247I/BLT.19.247494

Otto, M. (2013, 01 / 01 /). Community-associated MRSA: What makes them special? International Journal of Medical Microbiology. https://doi.org/10.1016/j.ijmm.2013.02.007

Redziniak, D. E., Diduch, D. R., Turman, K., Hart, J., Grindstaff, T. L., MacKnight, J. M., \& Mistry, D. J. (2009). Methicillinresistant Staphylococcus aureus (MRSA) in the athlete. International Journal of Sports Medicine 30, 557-562. https://doi. org/10.1055/s-0029-1214382

Rutala, W. A., Gergen, M. F., \& Weber, D. J. (2012). Efficacy of different cleaning and disinfection methods against Clostridium difficile spores: Importance of physical removal versus sporicidal inactivation. Infection Control and Hospital Epidemiology, $33(12), 1255-1258$.

Rutala, W. A., \& Weber, D. J. (2016). Disinfection, sterilization, and antisepsis: An overview. American Journal of Infection Control, 44(5, Supplement), el-e6. https://doi.org/https://doi.org//0.1016/j.ajic.2015.10.038

Ryan, K. A., Ifantides, C., Bucciarelli, C., Saliba, H., Tuli, S., Black, E., \& Thompson, L. A. (20II). Are gymnasium equipment surfaces a source of staphylococcal infections in the community? AJIC (American Journal of Infection Control), 39(2), I48-I50. https://doi.org/10.1016/j.ajic.2010.06.006

Stiefel, U., Cadnum, J. L., Eckstein, B. C., Guerrero, D. M., Tima, M. A., \& Donskey, C. J. (20II). Contamination of hands with methicillin-resistant Staphylococcus aureus after contact with environmental surfaces and after contact with the skin of colonized patients. Infection Control Hospital Epidemiology, 32(2), 185-187.

Sun, X., Shi, Y., Zeng, Q., Wang, Y., Du, D., Wei, N., Xie, R., \& C., C. (2013). Determinants of health literacy and health behavior regarding infectious respiratory diseases: A pathway model. BMC Public Health, 13(I), I-8. https://doi.org//0.1/86/I47/ 2458-|3-26|

White, K. M., Jimmieson, N. L., Obst, P. L., Graves, N., Barnett, A., Cockshaw, W., Gee, P., Haneman, L., Page, K., Campbell, M., Martin, E., \& Paterson, D. (2015). Using a theory of planned behaviour framework to explore hand hygiene beliefs at the '5 critical moments' among Australian hospital-based nurses. BMC Health Services Research, 15(29), 2-9. https://doi.org/ https://doi.org/I0.1/86/s12913-015-07/8-2

Williamson, D. A., Roberts, S. A., Ritchie, S. R., Coombs, G. W., Fraser, J. D., \& Heffernan, H. (20l3). Clinical and molecular epidemiology of methicillin-resistant Staphylococcus aureus in New Zealand: Rapid emergence of Sequence Type 5 (ST5)SCCmec-IV as the dominant community-associated MRSA clone. PLoS ONE, 8(4), I-7. https://doi.org//0.137//journal. pone.0062020

Wong, J. W. H., Ip, M., Tang, A., Wei, V. W. I., Wong, S. Y. S., Riley, S., Read, J. M., \& Kwok, K. O. (2018). Prevalence and risk factors of community-associated methicillin-resistant Staphylococcus aureus carriage in Asia-Pacific region from 2000 to 2016: A systematic review and meta-analysis. Clinical Epidemiology, 10, 1489-1501. https://ezproxy.toiohomai.ac.nz/ login?url=https://search.ebscohost.com/login.aspx?direct=true\&db=edsdoj\&AN=edsdoj.48b9dab0edca4be0af546I53 Id fc70bb\&site=eds-live

World Health Organisation. (2002). Prevention of hospital-acquired infections. https://www.who.int/csr/resources/publications/ whocdscsreph200212.pdf

World Health Organisation. (202I). Coronavirus disease (COVID-19) advice for the public. https://www.who.int/emergencies/ diseases/novel-coronavirus-2019/advice-for-public

Zinder, S. M., Basler, R. S., Foley, J., Scarlata, C., \& Vasily, D. B. (2010). Athletic Trainers' Association Position Statement: Skin diseases. Journal of Athletic Training (National Athletic Trainers' Association), 45(4), 4ll-428. https://doi.org/ 10.4085/I0626050-45.4.4II 